\title{
Rethinking early childhood workforce sustainability in the context of Australia's early childhood education and care reforms
}

Tamara Cumming ${ }^{1,2^{*}}$, Jennifer Sumsion ${ }^{1}$ and Sandie Wong ${ }^{1,2}$

\author{
* Correspondence: \\ tcumming@csu.edu.au \\ ${ }^{1}$ Research Institute for Professional \\ Practice, Learning and Education, \\ Charles Sturt University, Wagga \\ Wagga, Australia \\ ${ }^{2}$ School of Teacher Education, \\ Charles Sturt University, Panorama \\ Ave, Bathurst, NSW 2795, Australia
}

\begin{abstract}
Early childhood workforce sustainability is an important issue, with implications for children, families and national productivity, as well as for educators themselves. Yet, in many national contexts, workforce challenges continue to undermine efforts to support sustainability. In this article, we evaluate efforts to address early childhood workforce challenges in the Australian context, where extensive early childhood reforms are underway. We argue that attempts to address workforce challenges in current policy initiatives are limited and may be insufficient for sustaining the early childhood workforce in the long term. Given the critical role that the early childhood workforce plays in Australia's early childhood reform agenda, we then consider how workforce sustainability could be rethought and other possibilities generated for addressing entrenched workforce challenges. We conclude by arguing that greater attention to the everyday politics of educators' practice, along with the forces shaping these milieux, may be a way of generating new possibilities for supporting workforce sustainability.
\end{abstract}

Keywords: Early childhood education; Early childhood educators; Early childhood teachers; Post structural theory; Australia

\section{至

\section{Background}

Early childhood educators ${ }^{\mathrm{a}}$ [referred to hereafter as 'educators'], and the workforce they comprise, are critical to 'universally accessible, high-quality ECE provision' (International Labour Organization 2014, 6) that best supports good outcomes for children, families and economic productivity (Organisation for Economic Co-Operation and Development [OECD] 2006; Gable et al. 2007). Yet, across many national contexts, challenges in attracting and retaining educators for many parts of the prior-to-school sector (all education and care that occurs before formal schooling begins) make it difficult to sustain the workforce over time. An extensive body of research concerned with workforce challenges has consistently suggested that to be effective, policy efforts need to address multiple challenges at setting, community and policy levels (as reviewed by the Institute of Medicine and National Research Council [IofM and NRC] 2012). However, as we discuss below, rather than taking a comprehensive approach, many policy initiatives tend to address only some aspects of workforce sustainability.

(c) 2015 Cumming et al.; licensee Springer. This is an Open Access article distributed under the terms of the Creative Commons Attribution License (http://creativecommons.org/licenses/by/4.0), which permits unrestricted use, distribution, and reproduction in any medium, provided the original work is properly credited. 
In Australia for example, efforts are being made to address workforce challenges as part of the extensive early childhood reform agenda that is currently being implemented. An illustration of the parts of the reform agenda specifically concerned with the workforce appears in Figure 1 (below). As this figure shows, the Early Years Workforce Strategy (Standing Committee on School Education and Early Childhood [SCSEEC] 2012) is a key part of the broader approach to early childhood sector reform. The workforce strategy frames a range of initiatives, providing funding support for educators to gain or improve their qualifications, and (to a lesser extent) support ongoing professional development and recognition. Workforce sustainability is a central tenet of the workforce strategy - as evident in its aim to: 'deliver a sustainable, highly qualified and professional workforce' (SCSEEC 2012, 3). The qualifications and professionalism foci of the workforce strategy (and its initiatives) are likely to go some way to addressing the identified skills and staff shortages in early childhood education roles in Australia (Bretherton 2010). However, given what is known about effective approaches to workforce sustainability (also detailed further below), we argue that the approaches offered by the Australian Workforce Strategy and initiatives are limited and may prove insufficient to sustain the early childhood workforce in the long term.

Nevertheless, developing a capable and effective early childhood workforce is still critical to achieving the goals of the early childhood reform agenda (Council of Australian Governments [COAG] 2009a). Accordingly, to open other possibilities for addressing entrenched workforce challenges and supporting workforce sustainability, our purpose in this article is twofold. Our first purpose is to speculate about the likely effectiveness of Australia's early childhood workforce strategies; our second is to think differently about concepts of sustainability and the politics of educators' practice and consider how these might assist in generating other possibilities.

We begin our discussion with a brief review of international literature concerned with commonly documented challenges relating to the early childhood workforce, in order to highlight the scope and complexity of these challenges. Next come details of some of the context and content of Australia's early childhood reforms, with a

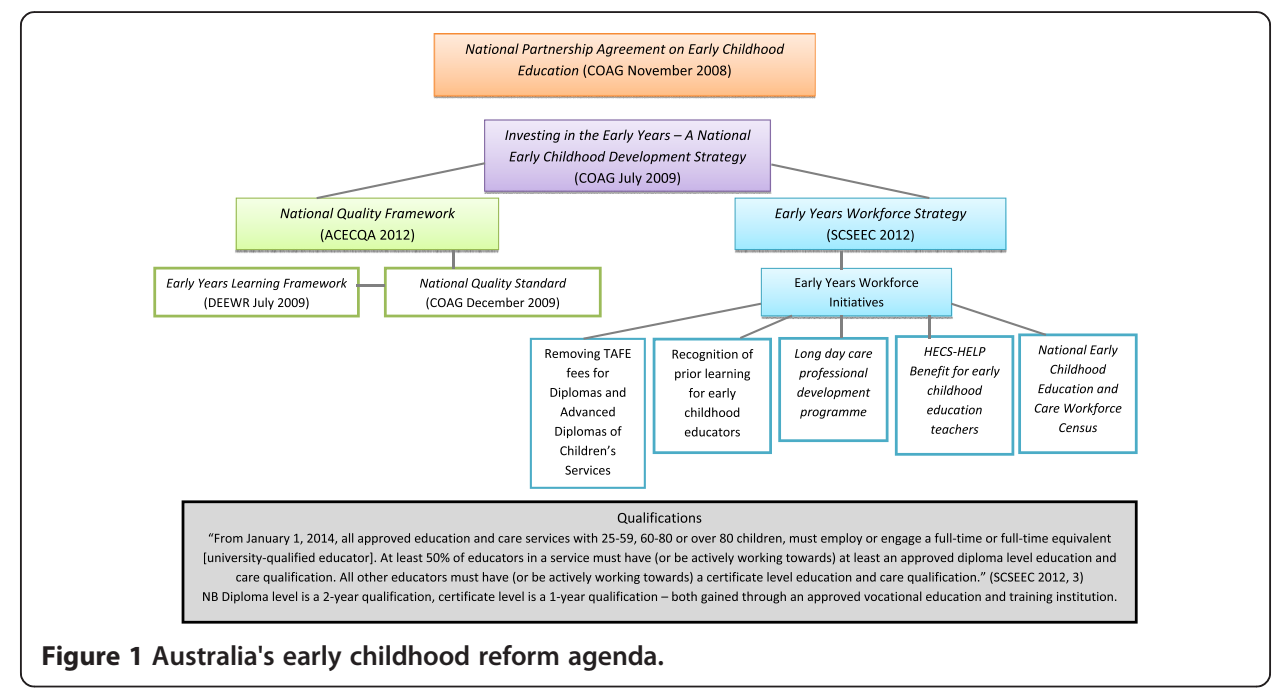


focus on parts of the reforms relating to the early childhood education workforce. We then profile Australia's early childhood workforce, including some of the key workforce challenges faced in the Australian context. This is followed by a critical reading of the Early Years Workforce Strategy (SCSEEC 2012), informed by research literature concerned with connections between workforce qualifications, retention and professionalism. In particular, we highlight what we see as some potential limitations of the workforce strategy for the long-term sustainability of the early childhood workforce.

In the final section of the article, we offer ways of thinking differently about sustainability. In particular, we consider how a process-oriented conceptualisation of sustainability (rather than one assuming sustainability can be 'delivered' (SCSEEC 2012, 3) might inform efforts to address entrenched workforce challenges. We also draw upon Deleuze and Guattari's (1987) ideas about flows of micro- and macro-politics to suggest the potential of micro-politics of educators' practice as a means of thinking further about the macropolitics of workforce sustainability. We conclude by offering suggestions for research attending to 'less tangible' aspects of educators' practice, and the politics of their negotiation, as a way of continuing to think differently about workforce sustainability and perhaps to generate new possibilities for supporting it.

\section{Early childhood workforce challenges}

Among the most commonly documented challenges relating to the early childhood workforce are: incommensurate pay (United Nations Children's Fund [UNICEF] 2008), lack of professional status (IofM and NRC 2012), workplace stress (Whitebook and Ryan 2011) and limited career development opportunities (Productivity Commission 2011). These factors appear to consistently work in combination to '...influence who enters and stays in the workforce, as well as the quality and effectiveness of their services for children and families' (IofM and NRC 2012, 61). High levels of turnover (between workplaces) and attrition (from the field altogether) have widespread implications (Whitebook and Ryan 2011) for educators, families and the broader economy. For example, an undersupply of educators (due to challenges such as attrition) can jeopardise the availability and affordability of good quality early childhood education and care that is crucial to many parents' workforce participation (UNICEF 2008; Bretherton 2010).

At the same time, staff turnover and attrition have perhaps the most far-reaching and potentially long-lasting consequences for educators and children. In particular, turnover and attrition can be detrimental to educators, families and children developing and maintaining the relationships that best support children's learning and development experiences (OECD 2006; Gable et al. 2007). Additionally, in settings with high staff turnover, the quality of professional practice and professional culture can be undermined by recurrent change and/or the loss of pedagogical leadership (Whitebook and Ryan 2011; IofM and NRC 2012). Turnover can also contribute to levels of stress (Groeneveld et al. 2012) and depression among educators who remain in a setting with high rates of turnover (de Schipper et al. 2008). Experiences such as these may potentially undermine educators' capacity for high quality practice, as well as for their personal well-being (Whitebook and Ryan 2011).

However, sustaining educators in the sector may not always be desirable - for example, if their motivation for remaining in the field is only due to a lack of other work 
opportunities (IofM and NRC 2012) or they are not fully committed and engaged with children and families (Bretherton 2010). Efforts to better support and sustain educators and the workforce therefore need to be premised on attracting and retaining adequate numbers of appropriately qualified and capable educators.

As this brief overview of workforce challenges suggests, there is much at stake in the development of effective strategies for supporting workforce sustainability. Yet, evidence from many national contexts suggests that challenges such as those documented above are entrenched problems (UNICEF 2008). In the Australian context, the complexity of addressing these challenges to workforce sustainability is magnified by factors such as: a legacy of a bifurcated education/care system; multiple government funding pathways; and diverse service ownership structures and regulatory jurisdictions associated with Australia's federated political system (Productivity Commission 2011). Despite this complex context, the Australian Government and state and territory governments, under the auspice of the Council of Australian Governments $\left(\mathrm{COAG}^{\mathrm{b}}\right)$, have begun integrating a highly fragmented sector and have begun to address workforce challenges. The next part of the article gives an outline of the reform agenda, then, profiles Australia's early childhood workforce and some of the existing challenges to its sustainability.

\section{Australia's early childhood education reform agenda}

Since 2007, the implementation of an extensive early childhood reform agenda (COAG 2009a) has been underway in Australia. These reforms were prompted (in part) by Australia's relatively poor performance against 2006 OECD indicators of investment in early childhood education ${ }^{c}$, by compelling evidence of the importance of early childhood education in supporting positive outcomes for children and a highly fragmented system of service provision and regulation (Logan, Sumsion and Press: The shaping of quality in Australian early childhood education and care: what can we learn from the critical juncture? forthcoming). Although these challenges had been reported for at least a decade, the reform agenda was finally made possible by a renewed commitment to social investment that accompanied the change from a conservative to a more progressive federal government in 2007 (Brennan 2011).

The early childhood reform agenda '...covers children from before birth to eight years and aims to improve the health, safety, early learning and wellbeing of all children and better support disadvantaged children to reduce inequalities' (COAG 2009a, 4). In order to fund this agenda, Australia's federal government and its state and territory governments increased their investment in early childhood education by over $53 \%$ between 2007-08 and 2011-12 (Productivity Commission 2013). Figure 1 illustrates some of the main aspects of the early childhood reform agenda that relate to the arguments about workforce sustainability that are made in this article. Brief details of each aspect are included after the diagram.

- The National Partnership on Early Childhood Education (COAG 2008) was established: '...as a starting point for joint [government] action to improve the supply and integration of early childhood services, including child care and early learning and development' (COAG 2008, 3). A key commitment of this 
National Partnership is to 'ensure universal access to [15 hours of] quality early childhood education in the year before school' (COAG 2008, 1). This policy is closely connected to workforce sustainability because of the need for greater numbers of appropriately qualified educators to meet the increased demand this policy has generated (see 'Qualifications' box in Figure 1 for further details).

- The National Early Childhood Development Strategy (COAG 2009a, 4) was established with a 'shared vision... that by 2020 all children have the best start in life to create a better future for themselves and for the nation'. This Strategy integrated (and in some cases established) a complex range of early childhood education, health and family services and targeted strategies to address Aboriginal and Torres Strait Islander disadvantage (Australian Government Department of Education 2014).

- The National Quality Framework (Australian Children's Services Education and Care Quality Authority 2012), the National Quality Standard (COAG 2009b) and quality rating system, and Australia's first national early childhood curriculum guide The Early Years Learning Framework [EYLF] (DE 2009) also have implications for workforce sustainability. The National Quality Standard focuses on the importance of qualifications and higher staff to child ratios as 'key influences on the quality of care, while the EYLF provides a guide to assist educators to provide 'quality teaching and learning' (DE 2009, 5).

- The Early Years Workforce Strategy (SCSEEC 2012, 3) aims to: 'deliver a sustainable, highly qualified and professional workforce' by focusing on a range of measures for improving educators' qualifications (and to a lesser extent, professional recognition). As indicated in Figure 1, a number of targeted workforce initiatives are part of this workforce strategy.

\section{Australia's early childhood workforce Profile}

In 2013, Australia's early childhood workforce was estimated at 153,155 (Australian Government Department of Education [DE] 2014). It has been growing at around 4\% per year for the last 10 years, with especially strong growth in the parts of the workforce employed by long day care (that operate for up to $11 \mathrm{~h}$ daily, year round, and may accept children from 0 to 5 years) and preschool (that operate for 3 to $6 \mathrm{~h}$ daily, during school terms only, and usually accept children aged 3 to 5 years) services. Well over half of the early childhood workforce is employed in centre-based, approved care services ${ }^{\mathrm{d}}$ - with $49.4 \%$ working in long day care services and $17.6 \%$ working in 'preschool' services (DE 2014). A further $22 \%$ work in services for school-aged children (provided before or after school or during vacation times); $9 \%$ in family day care (educators providing services in their own home, for up to five children); and less than $2 \%$ (combined) in occasional care centres and in-home care (usually one on one care of a child in the child's home) (Productivity Commission 2014).

According to the 2013 National Early Childhood Education and Care Workforce Census, over $80 \%$ of educators working in approved care services in Australia had an early childhood-related qualification - an increase of over 10\% in 3 years since the previous 
workforce census. Of those with early childhood-related qualifications: $6 \%$ had a (3 or 4 year) bachelor degree (from a university); $28 \%$ had a diploma qualification; and $36 \%$ a certificate qualification (from a vocational education and training institution) (The Social Research Centre 2014). In response to the higher staff ratios and qualification requirements mandated by the new National Quality Standard (COAG 2009b), demand for both vocationally and university-qualified educators has substantially increased (Productivity Commission 2014, 487) and is expected to remain high.

\section{Workforce challenges}

Some of the challenges relating to Australia's early childhood workforce sustainability are consistent with experiences in other national contexts, in particular: pay that is incommensurate with the skill and responsibility required of educators, educators perceiving that there is a lack of public recognition of their professionalism and, that work in other sectors offers the same pay but is perceived to be less stressful (Productivity Commission 2011). Also similarly to other national contexts, rates of staff turnover between workplaces are high in Australia - estimated at between 25\% and 37\% per year (depending on jurisdiction and job classification) (Community Services Ministers' Advisory Council 2006). Staff shortages are also widespread and, along with turnover, are especially problematic among diploma and university-qualified educators, in regional and remote areas and in the long day care workforce. In addition, there are difficulties attracting and retaining educators (of all qualifications) for indigenous-focused services (Productivity Commission 2014). A shortage of service leaders also appears to create additional pressure; with educators sometimes promoted beyond their skills, experience and knowledge (Bretherton 2010). As some advocates have suggested, without ongoing mentoring and skills development, these leaders may subsequently 'burn out' and leave the sector (United Voice - The Childcare Union 2011).

With these challenges in mind, we now go on to speculate about the effectiveness of Australia's workforce initiatives for sustaining the early childhood workforce in the longer term. We undertake this task via a critical reading - that is, by questioning and evaluating - the claims of the Early Years Workforce Strategy (SCSEEC 2012) when read through existing research literature. We then consider how other possibilities for addressing workforce challenges could be generated by (better) mobilising discourses ${ }^{\mathrm{e}}$ of sustainability and ideas about micro- and macro-political flows.

\section{The early years workforce strategy: a critical reading}

\section{A highly qualified workforce?}

The stated purpose of the Early Years Workforce Strategy is to: 'build and support the early childhood education and care profession both in the short term and into the future' (SCSEEC 2012, 2). However, the Strategy's focus on increasing numbers of more highly qualified educators, and offering ongoing professional development, addresses only some of the issues known to challenge workforce sustainability. In addition, some problematic connections are made between workforce development strategies and staff retention in the Early Years Workforce Strategy. In particular, the strategy is premised on the idea that 'training' the workforce will lead to 'retaining' it (DE 2014). Although 
qualifications in early childhood education are generally thought to be beneficial (by contributing to 'higher quality learning outcomes' for children (DE 2014, n.p.), qualifications themselves are not necessarily predictive of retention (Torquati et al. 2007; Ryan and Ackerman 2005). Indeed, retention problems can be exacerbated as university-qualified educators can be attracted away from the prior-to-school sector to alternative career options (especially teaching in schools) where pay and conditions are better (Bretherton 2010; Productivity Commission 2014).

It also seems to be the case that some educators entering the early childhood workforce after completing pre-service education can find working conditions in the early childhood sector very different to what they anticipated or early childhood practice far more complex than they expected (Sumsion 2003, 2004; Noble and Macfarlane 2005). Disillusionments such as these, along with a lack of capacity to negotiate them, seemed to contribute to turnover or attrition of educators in the studies cited here. These critiques should not be read as arguments against the benefits of higher qualifications for the quality of educators' practice. Rather, we are arguing that an effective workforce sustainability strategy (in terms of retention) needs to recognise and address the risks inherent in large numbers of educators completing qualifications, then being offered little in return for the effort and expense of having gained these qualifications.

\section{A professional workforce?}

Another area of the Early Years Workforce Strategy we wish to explore through our critical reading concerns discourses of professionalism and professionalisation. As governments in many national contexts set 'ambitious policy goals' (Urban 2008, 135) for developing early childhood education systems, there has also been increasing focus upon professionalising the early childhood workforce.

Through an emphasis upon measurable, standardised aspects of early childhood practice such as credentialling (Osgood 2010) and qualifications (Urban 2008), policy initiatives can conflate professionalisation with professionalism, thereby shaping discourses of professionalism in limited ways (as Osgood 2006 reports, for example).

The Early Years Workforce Strategy appears to reflect this agenda through its emphasis on the development of educators' professionalism via the acquisition of 'specialist skills and knowledge' and participation in 'professional development and job-based training opportunities' (SCSEEC 2012, 8). Similarly, increased professional status for educators is linked to the establishment of measurable 'professional standards' (8) and the 'improved and nationally consistent qualification requirements' (SCSEEC 2012, 4) of the National Quality Framework. While these are all relevant and important elements of the professionalisation of the workforce, the emphasis upon these elements in the workforce strategy, could also limit possibilities for conceptualising professionalism in early childhood practice. This is problematic insofar as others have noted many other complex ways in which professionalism is inflected in early childhood practice (Urban 2010). For example, an emphasis upon the production and application of expert knowledge (Urban 2008) can obscure the role of 'hidden dimensions of [early childhood] professional practice' that are critical to educators making 'sound judgement $[\mathrm{s}]$ in the use of personal/professional, theoretical and practical knowledge' (Goodfellow 2003, p. 48). Similarly, knowledge-based discourses of professionalism may ignore the important 
relational aspects of early childhood practice (Dalli 2008) that are important to educators' own conceptualisations of their professionalism (Ortlipp et al. 2011).

Linking improvements to professional status only with large-scale reforms can also be problematic. For example, diverse (and sometimes divisive) conceptualisations of and claims to professional status can enable or constrain educators' sense of professionalism. Brooker (2010), for example, reports on ways that parents' validation (or invalidation) of educators' professional status (in two UK settings) had different effects on educators' sense of professionalism. Similarly, Kim (2004) study with South Korean educators suggested that claims to professionalism were contested between educators themselves, depending on whether they held a university rather than a vocational qualification.

The type of early childhood service in which an educator works can also inflect the professionalism attributed to them. This is often the case in the Australian context, where educators in preschools are sometimes viewed as more professional than those with the same qualifications working in long day care services. This is partly due to persistent misconceptions that preschools are always more focused on education than long day care services whose focus is upon 'care' (Cheeseman and Torr 2009). Differences in working conditions between service types can exacerbate status differentials too, with educators working in preschools generally having access to 'higher salaries, shorter hours and more holidays' (Productivity Commission 2014, 489) than their identically qualified colleagues working in long day care services.

These examples suggest that professionalism in early childhood practice is far more complex than conveyed by the limited discourses mobilised in the Early Years Workforce Strategy. Moreover, that while a policy focus on large-scale elements of professionalisation are important, so too is attention to the ways workplace cultures and relations with families and colleagues have the capacity to enable or constrain educators' professional status. For these reasons, we argue that the focus in the Early Years Workforce Strategy upon professionalisation via credentialling, qualifications and professional learning may not be sufficient to improve perceptions or recognition of the complexity of educators' professionalism.

\section{An appropriately remunerated workforce?}

A final issue we wish to explore in our critical reading of the workforce strategy concerns wage equity. In 2011, a research report on the Australian early childhood workforce (Productivity Commission, $x x x$ ) emphasised the importance of 'pay and conditions, both absolute and relative to other occupations' as a key incentive for workers 'to gain the appropriate qualifications, to enter the workforce, to upgrade their qualifications where necessary, and to remain in the workforce'. Despite these recommendations, the subsequent workforce strategy stated that: 'matters such as lower pay and conditions compared to other sectors are recognised as affecting professional status but are outside the scope of the strategy, as they are for employers and employees to negotiate' (SCSEEC 2012, 4). While issues relating to pay can dominate discussions of workforce sustainability, wages that are commensurate with the skills and responsibility of early childhood practice have been consistently identified as a major part of an effective retention strategy (IofM and NRC 2012; International Labour Organization 
2014). By failing to recognise this interrelationship, and the need for governmentsponsored (if not funded) measures that support wage equity, the question of 'who pays?' for Australia's 'sustainable, highly qualified and professional workforce' (SCSEEC 2012, 3) continues to be displaced to families and 'the market' to determine (Brennan 2011).

The likelihood of wage equity being successfully addressed through market mechanisms seems remote however, as the costs and wage implications of better-paid educators are often seen as antithetical to the interests of employers and/or families (Woodrow 2007; Lyons 2011). Recent Productivity Commission reports (2011, 2014), for example, have recorded the reluctance of educators to ask for higher wages, and of employers to offer them, because increased costs would be most likely passed on to families in the form of higher fees, potentially leading to the removal of some children from services. Whitebook and Ryan (2011) offer a different perspective on this issue, arguing that wages and benefits 'that support adult well-being' are important features of 'the adult work environment $\mathrm{f}^{\mathrm{f}}$ that in turn, impacts educators' 'ability to apply their knowledge and skills' effectively (6). Seen in this way, educators' rights to fair pay, and children's and families' interests, need not be seen as mutually exclusive. It could also be argued that if calls for improved public recognition of professional status are not matched by improved remuneration, the undervaluation of educators' practice might be perpetuated (Lyons 2011).

\section{Reshaping the reform agenda?}

The risks of the current limited approach to workforce sustainability, and some of the problematic connections between qualifications, professionalism and wage equity that we have discussed above, may be magnified by a changing political climate in Australia. Since the election (in late 2013) of a more conservative federal government, funding commitments concerned with the workforce initiatives (made by the government originally responsible for the reform agenda) have been revoked. Changes have included: the removal (in 2015) of fee subsidies for educators living in 'areas of high need ${ }^{\text {gg }}$ who are undertaking university qualifications (DE 2014) and the introduction of a new professional development fund available only to those working in long day care services (Early Childhood Australia 2014). While on one hand the new professional development fund is putting support into the service type reported to be experiencing the greatest workforce challenges (Productivity Commission 2014), the removal of fee subsidies is likely to reduce the numbers of university-qualified teachers graduating and in the areas identified as in highest need.

In addition, a substantial change in the focus of early childhood policy has accompanied the change of government. This change is evident, for example, in the contrasting terms of reference of the 2011 Productivity Commission ${ }^{\text {h }}$ enquiry (whose research informed the original early childhood workforce initiatives) and those of an enquiry that is (as of late 2014) underway.

The Council of Australian Governments (COAG) has agreed on common strategic frameworks to guide government action on early childhood development, schooling and vocational education and training (VET) across Australia. Building the capability and effectiveness of the workforces in these sectors, particularly for Indigenous 
people, will be critical to achieving the outcomes agreed in these frameworks.

(Productivity Commission 2011,iv)

By contrast, the terms of reference for the Productivity Commission enquiry $(2014, v)$ begin with the statement that:

The Australian Government is committed to establishing a sustainable future for a more flexible, affordable and accessible child care and early childhood learning market that helps underpin the national economy and supports the community, especially parent's choices to participate in work and learning and children's growth, welfare, learning and development.

In this way, discourses of national productivity and early childhood learning as a 'market' are amplified, while any focus on supporting the early childhood workforce (so that it might contribute to these foci) is absent. It seems that despite the extensive body of literature outlining the need for cross-jurisdictional, multi-level workforce strategies, Australia's current federal government is taking a fragmentary approach to workforce sustainability, just as the early childhood sector itself is becoming more integrated via national quality standards and curricular guidelines.

We are not alone in our concerns regarding the effectiveness of Australia's current workforce initiatives for delivering on the policy intent to build a 'sustainable, high quality ECEC workforce' (SCSEEC 2012, 3). For example, in relation to the emphasis upon gaining or upgrading qualifications in the Early Years Workforce Strategy, Australia's Health and Community Services Workforce Council points out that:

Initiatives to increase the supply of ECD [early childhood development] workers have often resulted in high churn in industries with many people being trained but only a small proportion of these staying in the industries. Training is one part of workforce planning and development and a primary focus on training and qualifications often discounts other critical factors... (quoted in Productivity Commission 2011, 287).

Similar concerns are also raised by Cheeseman and Torr (2009, 71), who note of the Workforce Initiatives (as illustrated in Figure 1) that: 'While attention is given to recruiting students into training places, there has at this time been no announcement regarding strategies to address the long-term difficulties of retaining staff in the prior to school sector'. Five years later, additional, targeted strategies for workforce retention have not been introduced, demand for educators continues to rise and dissatisfaction is reported to have increased among educators working in priorto-school settings, especially long day care, preschool and family day care settings (The Social Research Centre 2014, 4). Given the limited focus of the workforce strategy, the problematic premises underpinning its focus on qualifications, the exclusion of measures to improve wage equity, the revocation of some funding support and the long-term sustainability the strategy is aiming for may not be 'delivered' (SCSEEC 2012, 3). 


\section{(Re)thinking the sustainability of the early childhood workforce}

In the critical reading above, we outlined some of the reasons that we (and others) contend there may be limits to the effectiveness of the workforce strategy for long-term workforce sustainability. Yet, the premise with which we opened the article remains salient - that sustaining early childhood educators, and the workforce they comprise, is critical to achieving good outcomes for children through early childhood education. With this in mind, we now turn to thinking about how discourses of sustainability could be better mobilised to open up other possibilities for addressing entrenched workforce challenges. We begin with a brief discussion of two conceptualisations of sustainability then put these ideas to work in rethinking ideas of workforce sustainability.

\section{Discourses of sustainability}

Sustainability is a powerful concept for thinking about equity, resources, obligations and the connections of the present and future. Its origins lie in concerns about global environmental degradation and the need to balance the needs of the present with those of the future (World Commission on Environment and Development 1992). Despite its powerful discursive potential for guiding transformation, the ubiquity of sustainability in policy and public discussions can reduce this potential to a cliché. This effect (evident, we argue, in the ways workforce sustainability is used in Australia's Early Years Workforce Strategy) may be to limit rather than amplify its transformative potential as a concept. However, sustainability can also be conceptualised as a process that is:

dynamic rather than static, as a means rather than an end, as a challenge for continuous cultural and social change rather than a once and for all measurable outcome, and... challenging in terms of the development of global solidarity and justice (Hägglund and Pramling Samuelson 2009, 52).

This conceptualisation disrupts the idea that sustainability is something that can be (in the words of the workforce strategy) 'delivered' (SCSEEC 2012, 3). Rather, through this conceptualisation, sustainability can be understood as an ongoing process that has a politics of change and negotiation and interconnections with the local and global. This understanding may then offer another way of thinking about workforce sustainability - as a negotiated, ongoing process of transformation rather than an end state.

An expanded conceptualisation of sustainability also invites different questions - the purpose of which is to open new possibilities, not simply to define what things are, or to continue to work from 'stability of the already given' (May 2005, 121). Research drawing on post-structural theory to rethink early childhood pedagogies has suggested (for example) that 'the large-scale is [not necessarily] more significant than what might be happening locally at the micro level' (Blaise 2013, 189). Indeed, as Olsson (2009) (a researcher drawing on Deleuze and Guattari's concepts) argues that '....it is always the micro-political ${ }^{\mathrm{i}}$ that decides the making or breaking of the process' $(2009,75)$. As we now go on to discuss, looking beyond known workforce challenges, and large-scale approaches (such as those mentioned earlier in the article), and applying a different concept of sustainability could be a way of generating new thinking about workforce sustainability. 


\section{Rethinking workforce sustainability}

One way of turning from a large- to a small-scale approach to workforce sustainability is to focus on educators' practice. Research concerned with ways educators negotiate the many elements of their practice has, for example, illuminated ways that educators developed resilience, reflexive capacity and other strategies allowing them to negotiate potentially repressive conditions (for an interpretative meta-analysis of some of this research, see Cumming et al. 2013). For example, educators in an Australian study were reported to have exercised a collective 'ethic of resistance' to dominant regulatory discourses (Fenech et al. 2010, 96), through sustained critical reflection on practice. Similarly, a study conducted in the UK reported on educators' invocation of a 'professionalism from within' (Osgood 2010, 126) that allowed them to express ways of being a professional that did not rely upon the dominant discourses of professionalism otherwise available to them. Further exploration of educators' capacities for reworkings of the 'little territories of the everyday' (Rose 1999, 280) (in ways such as those outlined above) might help generate other possibilities for sustaining educators and the workforce they comprise. This may be especially so in the Australian context, where the complexities of early childhood practice have already been recognised in policy documents (Cumming et al. 2014).

At the same time, as Press and Skattebol (2007) and Osgood (2009) caution, an increased focus on the micro-politics of educators' practice should not preclude further attention to the productive capacity of macro-political flows to effect change (through policy initiatives in particular). For example, as a means of balancing the possibilities offered by micro- and macro-political movements, Press and Skattebol promote the possibilities of: '...political action that recognise[s] and generate[s] localised responses, whilst at the same time engendering policy that enables more broadly based social justice' (180). In the Australian context, this could take the form of continued engagement by the early childhood sector in the 'contestation involved in policy development and implementation' (Press and Skattebol 2007, 182) via, for instance, lobbying ministers, promoting the impacts of changes or contributing to the reshaping of the early childhood reform agenda.

\section{Concluding thoughts}

In this article, we have argued that addressing entrenched workforce challenges such as sustainability is in the interests of children, families and the broader economy, as well as educators themselves. However, as we have also endeavoured to show, the focus in Australia's Early Years Workforce Strategy on qualifications and credentials-based discourses of professionalism offer only a limited approach to supporting workforce sustainability. This approach may be (we argue) inadequate to support and sustain the early childhood workforce in the long term, nor effectively support the goals of the broader reform agenda.

Looking beyond the known challenges to workforce sustainability has helped generate new possibilities for thinking differently about supporting and sustaining Australia's early childhood workforce. In particular, better mobilising discourses of sustainability, and further exploration of the micro-politics of educators' practice, are two ways we have suggested new possibilities could be generated for approaching seemingly entrenched workforce challenges. We have also recognised the potential of macro-political forces (in 
particular, policy initiatives) for addressing challenges in a more systemic way. Along with a focus on ways educators negotiate elements of early childhood practice then, exploring the relations between micro- and macro-politics - how they work and what they produce (to paraphrase Deleuze and Guattari 1987) - may be another way of generating additional possibilities for addressing workforce sustainability.

\section{Endnotes}

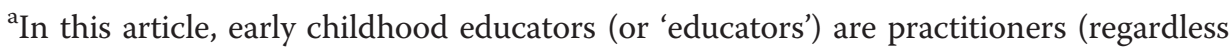
of level of qualification) who '...work directly with children in early childhood settings' (Australian Government Department of Education Employment and Workplace Relations 2009, 5).

${ }^{\mathrm{b}} \mathrm{COAG}$ is comprised of Australia's federal government, along with its six states, and two territory governments.

${ }^{c}$ Even in 2013, Australia's investment in early childhood education was still only around $0.4 \%$. This is $0.3 \%$ lower than the OECD average (Organisation for Economic Co-operation and Development 2013) and 0.6\% lower than the minimum recommended by (UNICEF 2008).

d'Approved care services (the dominant category of care) are those long day care, approved by government as meeting the eligibility standards and requirements to provide care for the purposes of Child Care Benefit (CCB). Long day care, family day care and outside school hours care are also required to satisfy the National Quality Framework. Approved care attracts both the Child Care Rebate (CCR) and CCB for those that use it' (Productivity Commission 2014, 77). Other non-mainstream services offered as part of the early childhood sector include: mobile child care services, Multifunctional Aboriginal Children's services (MACS), indigenous playgroups, outside school hours care, flexible services and indigenous enrichment programmes and crèches (Productivity Commission 2014, 92).

${ }^{\mathrm{e}} \mathrm{We}$ conceptualise discourses as codified, sometimes dominant ways of thinking and speaking about things. Discourses can have productive as well as repressive potential.

${ }^{\mathrm{f}}$ Features identified by Whitebook and Ryan included: the impacts of 'variations in staffing patterns and the background of other teachers' or 'the degree of support in the workplace for ongoing teacher development through policies related to mentoring, professional development opportunities and paid planning and meeting time' $(2011,6)$.

g'Areas of high need are defined as regional or remote areas, indigenous communities, or areas of high socio-economic disadvantage based on postcode location' (DE 2014).

${ }^{\mathrm{h}}$ The Productivity Commission is the Australian Government's independent research and advisory body on a range of economic, social and environmental issues affecting the welfare of Australians. Its role...is to help governments make better policies in the long term interest of the Australian community. [In particular] the Commission's focus is on ways of achieving a more productive economy' (Productivity Commission n.d.)

'Deleuze and Guattari's (1987) concepts of the micro- and macro-political are not sociological categories such as structure and agency that can infer an essential hierarchy and set of relations. Rather, they are types of movements - that regularise, organise and sometimes limit possibilities (macro-political movements) and that disrupt and reshape stabilisations (micro-political movements). These movements are understood to be mutually engaged in relays of stabilisation, de- and re-stabilisation that create the conditions of reality. 


\section{Competing interests}

The authors declare that they have no competing interests.

\section{Authors' contributions}

TC conceptualised the argument, conducted the policy analysis and interpretation, and drafted the manuscript: JS contributed to the arguments and scope of the analysis; both JS and SW provided critical revisions that also contributed to the policy interpretation and implications. All authors read and approved the final manuscript.

\section{Acknowledgments}

The authors gratefully acknowledge the extensive comments and suggestions given by peer reviewers of this article.

Received: 3 June 2014 Accepted: 15 January 2015

Published online: 11 March 2015

\section{References}

Australian Government Department of Education (2014). Early childhood workforce initiatives. Retrieved from http://education. gov.au/early-childhood-workforce-initiatives.

Australian Government Department of Education Employment and Workplace Relations. (2009). Belonging, being \& becoming: the early years learning framework for Australia. Canberra, Australia: DEEWR.

Blaise, M. (2013). Activating micropolitical practices in the early years: (Re)assembling the body in participant observations. In R Coleman \& J Ringrose (Eds.), Deleuze and research methodologies. Edinburgh: Edinburgh University Press.

Brennan, D (2011). Investing in childhood: the progress and the pitfalls. http://inside.org.au/investing-in-childhood-theprogress-and-the-pitfalls/.

Bretherton, T (2010). Developing the child care workforce: understanding 'fight' or 'flight' amongst workers. http://www. ncver.edu.au/publications/2261.html.

Brooker, L. (2010). Constructing the triangle of care: power and professionalism in practitioner/parent relationships. British Journal of Educational Studies, 58(2), 181-196. doi:10.1080/00071001003752203.

Australian Children's Services Education and Care Quality Authority (2012). The national quality framework. http://acecqa. gov.au/national-quality-framework/introducing-the-national-quality-framework.

Cheeseman, S, \& Torr, J. (2009). From ideology to productivity: reforming early childhood education and care in Australia. International Journal of Child Care and Education Policy, 3(1), 61-74.

Community Services Ministers' Advisory Council. (2006). National children's services workforce study. http://www.education. vic.gov.au/childhood/Pages/default.aspx 15364417.pdf.

Council of Australian Governments. (2008). National partnership agreement on early childhood education. Canberra: Council of Australian Governments.

Council of Australian Governments (2009a). Investing in the early years: a national early childhood development strategy. http://www.coag.gov.au/node/205.

Council of Australian Governments. (2009b). National quality standard for early childhood education and care and school age care. Canberra: Council of Australian Governments.

Cumming, T, Sumsion, J, \& Wong, S. (2013). Reading between the lines: an interpretative meta-analysis of ways early childhood educators negotiate discourses and subjectivities informing practice. Contemporary Issues in Early Childhood, 14(3), 223-240. doi:10.2304/ciec.2013.14.3.223

Cumming, T, Sumsion, J, Wong, S (2014). Early childhood practice and refrains of complexity. Early Years: An International Research Journal. doi:10.1080/09575146.2014.937796.

Dalli, C. (2008). Pedagogy, knowledge and collaboration: Towards a ground-up perspective on professionalism. European Early Childhood Education Research Journal, 16(2), 171-185. doi:10.1080/13502930802141600.

de Schipper, EJ, Riksen-Walraven, JM, Geurts, SAE, \& Derksen, JJ. (2008). General mood of professional caregivers in child care centers and the quality of caregiver-child interactions. Journal of Research in Personality, 42(3), 515-526. doi:10.1016/j.jp.2007.07.009.

Deleuze, G, \& Guattari, F. (1987). A thousand plateaus: capitalism and schizophrenia (B. Massumi, Trans.). London: Continuum.

Early Childhood Australia. (2014). Federal budget 2014-15: preliminary summary from Early Childhood Australia. Canberra, Australia: Early Childhood Australia.

Fenech, M, Sumsion, J, \& Shepherd, W. (2010). Promoting early childhood teacher professionalism in the Australian context: the place of resistance. Contemporary Issues in Early Childhood, 11(1), 89-105.

Gable, S, Rothrauff, TC, Thornburg, KR, \& Mauzy, D. (2007). Cash incentives and turnover in center-based child care staff. Early Childhood Research Quarterly, 22(3), 363-378. doi:10.1016/j.ecresq.2007.06.002.

Goodfellow, J. (2003). Practical wisdom in professional practice: the person in the process. Contemporary Issues in Early Childhood, 4(1), 48-63.

Groeneveld, MG, Vermeer, HJ, van ljzendoorn, MH, \& Linting, M. (2012). Caregivers' cortisol levels and perceived stress in home-based and center-based childcare. Early Childhood Research Quarterly, 27(1), 166-175.

Hägglund, S, \& Pramling Samuelson, I. (2009). Early childhood education and learning for sustainable development and citizenship. International Journal of Early Childhood, 41(2), 49-63.

Institute of Medicine and National Research Council (2012). The early childhood care and education workforce: challenges and opportunities: a workshop report. Washington, DC. http://www.nap.edu/openbook.php?record_id=13238\&page=1

International Labour Organization. (2014). ILO policy guidelines on the promotion of decent work for early childhood education personnel. Geneva: International Labour Office. http://www.ilo.org/wcmsp5/groups/public/_ed_dialogue/_-sector/ documents/normativeinstrument/wcms_236528.pdf.

Kim, M. (2004). Teachers' philosophical orientation and practices: a study of novice preschool teachers in South Korea. Contemporary Issues in Early Childhood, 5(3), 276-292.

Lyons, M. (2011). The professionalization of children's services in Australia. Journal of Sociology, 48(2), 115-131. doi:10.1177/1440783311407945. 
May, T. (2005). Gilles Deleuze: an introduction. Cambridge, UK: Cambridge University Press.

Noble, K, \& Macfarlane, K. (2005). Romance or reality? Examining burnout in early childhood teachers. Australian Journal of Early Childhood, 30(3), 53-58.

Olsson, LM. (2009). Movement and experimentation in young children's learning: Deleuze and Guattari in early childhood education. Abingdon, UK: Routledge.

Organisation for Economic Co-Operation and Development (2006). Starting strong II: early childhood education and care. www.oecd.org/newsroom/37424999.pdf.

Organisation for Economic Co-operation and Development (2013). Social expenditure database 2013. OECD Education database (Vol. PF3.1).

Ortlipp, M, Arthur, L, \& Woodrow, C. (2011). Discourses of the early years learning framework: constructing the early childhood professional. Contemporary Issues in Early Childhood, 12(1), 56-70. doi:/10.2304/ciec.2011.12.1.56.

Osgood, J. (2006). Deconstructing professionalism in early childhood education: resisting the regulatory gaze. Contemporary Issues in Early Childhood, 7(1), 5-14.

Osgood, J. (2009). Childcare workforce reform in England and 'the early years professional': a critical discourse analysis. Journal of Education Policy, 24(6), 733-751.

Osgood, J. (2010). Reconstructing professionalism in ECEC: the case for the 'critically reflective emotional professional'. Early Years: An International Research Journal, 3(2), 119-133. doi:10.1080/09575146.2010.490905.

Press, F, \& Skattebol, J. (2007). Early childhood activism, minor politics and resuscitating vision: a tentative foray into the use of 'intersections' to influence early childhood policy. Contemporary Issues in Early Childhood, 8(3), 180-191.

Productivity Commission (2011). Early childhood development workforce. http://www.pc.gov.au/projects/study/educationworkforce/early-childhood/report.

Productivity Commission (2013). Report on government services: early childhood education and care (Vol. 2). http://www. pc.gov.au/_data/assets/pdf_file/0020/121763/05-government-services-2013-chapter3.pdf.

Productivity Commission. (2014). Childcare and early childhood learning. Canberra: Draft Report.

Productivity Commission (n.d.). About the productivity commission. http://www.pc.gov.au/about-us.

Rose, N. (1999). Powers of freedom: reframing political thought. Cambridge, UK: Cambridge University Press.

Ryan, S, \& Ackerman, DJ. (2005). Using pressure and support to create a qualified workforce. Education Policy Analysis Archives, 13(23), 1-17.

Standing Committee on School Education and Early Childhood. (2012). Early years workforce strategy: the early childhood education and care workforce strategy for Australia. Melbourne, Australia: SCSEEC.

Sumsion, J. (2003). 'Bad days don't kill you; they just make you stronger': a case study of an early childhood educator's resilience. International Journal of Early Years Education, 11(2), 141-154.

Sumsion, J. (2004). Early childhood teachers' constructions of their resilience and thriving: a continuing investigation. International Journal of Early Years Education, 12(3), 275-290. doi:10.1080/0966976042000268735.

The Social Research Centre. (2014). 2013 national early childhood education and care workforce census. Melbourne, Australia: Department of Education. http://docs.education.gov.au/system/files/doc/other/nwc_national_report_final.pdf.

Torquati, JC, Raikes, H, \& Huddleston-Casas, CA. (2007). Teacher education, motivation, compensation, workplace support, and links to quality of center-based child care and teachers' intention to stay in the early childhood profession. Early Childhood Research Quarterly, 22(2), 261-275.

United Nations Children's Fund. (2008). The child care transition, innocenti report card 8. Florence: UNICEF Innocenti Research Centre.

United Voice (2011). Response to productivity commission draft report: early childhood development workforce. http:// www.pc.gov.au/_data/assets/pdf_file/0008/112121/subdr166.pdf.

Urban, M. (2008). Dealing with uncertainty: Challenges and possibilities for the early childhood profession. European Early Childhood Education Research Journal, 16(2), 135-152. doi:10.1080/13502930802141584.

Urban, M. (2010). Rethinking professionalism in early childhood: untested feasibilities and critical ecologies. Contemporany Issues in Early Childhood, 11(1), 1-7.

Whitebook, M, \& Ryan, S. (2011). Degrees in context: asking the right questions about preparing skilled and effective teachers of young children. New Jersey, USA: National Institute for Early Education Research.

Woodrow, C. (2007). W(H)|ther the early childhood teacher: tensions for early childhood professional identity between the policy landscape and the politics of teacher regulation. Contemporary Issues in Early Childhood, 8(3), 233-243.

World Commission on Environment and Development. (1992). Our common future. Indiana: Centre for Our Common Future. http://conspect.nl/pdf/Our_Common_Future-Brundtland_Report_1987.pdf.

\section{Submit your manuscript to a SpringerOpen ${ }^{\circ}$ journal and benefit from:}

- Convenient online submission

- Rigorous peer review

- Immediate publication on acceptance

- Open access: articles freely available online

- High visibility within the field

Retaining the copyright to your article

Submit your next manuscript at $\boldsymbol{~ s p r i n g e r o p e n . c o m ~}$ 